\title{
Recombinant Human Growth Hormone Plus Recombinant Human Insulin-Like Growth Factor-1 Coadministration Therapy in Short Children with Low Insulin-Like Growth Factor-1 and Growth Hormone Sufficiency: Results from a Randomized, Multicenter, Open-Label, Parallel-Group, Active Treatment-Controlled Trial
}

\author{
Philippe F. Backeljauw ${ }^{\mathrm{a}}$ Bradley S. Miller ${ }^{\mathrm{b}}$ Pascale Dutailly ${ }^{\mathrm{g}}$ Aude Houchard $^{\mathrm{h}}$ \\ Elizabeth Lawson ${ }^{c}$ Daniel E. Hale ${ }^{d}$ Barry Reiner $^{e}$ Mark A. Sperling $^{f}$ on behalf of \\ the MS316 Study Group \\ aDivision of Pediatric Endocrinology, Cincinnati Children's Hospital Medical Center, University of Cincinnati College of \\ Medicine, Cincinnati, Ohio, b Pediatric Endocrinology, University of Minnesota Children's Hospital, Minneapolis, Minn., 'Ipsen \\ US, Basking Ridge, N.J., ' Department of Pediatrics, University of Texas Health Science Center, San Antonio, Tex., e Private \\ Practice, Baltimore, Md., and fDivision of Pediatric Endocrinology, Children's Hospital of Pittsburgh, University of Pittsburgh \\ School of Medicine, Pittsburgh, Pa., USA; ${ }^{9}$ Ipsen Innovation, Les Ulis, and hlpsen Pharma, Boulogne-Billancourt, France
}

\section{Key Words}

Short stature · Growth hormone · Insulin-like growth factor-1

\begin{abstract}
Background/Aims: Growth hormone $(\mathrm{GH})$ and insulin-like growth factor-1 (IGF-1) both contribute to growth. To determine if recombinant human ( $\mathrm{h}$ )GH + rhlGF-1 therapy is more effective than rhGH alone to treat short stature, we assessed the efficacy and safety of coadministered $\mathrm{rhGH}+$ rhIGF-1 in short children with GH sufficiency and low IGF-1. Methods: In a 3-year, randomized, multicenter, open-label trial, patients with height SD score $\leq-2.0$ and IGF-1 SD score $\leq-1.0$ for age and sex, and with stimulated $\mathrm{GH} \geq 10 \mathrm{ng} / \mathrm{ml}$ for age and sex, were randomized to receive (all doses in $\mu \mathrm{g} / \mathrm{kg}$ / day): 45 rhGH alone (group A), 45 rhGH + 50 rhlGF-1 (group B), 45 rhGH + 100 rhlGF-1 (group C) or 45 rhGH + 150 rhlGF-1
\end{abstract}

(group D). Height velocity (HV) and $\Delta$ height SD score were measured. Results: The first-year HV (modified intention-totreat population) was $9.3 \pm 1.7 \mathrm{~cm} /$ year (group A), $10.1 \pm 1.3$ $\mathrm{cm} /$ year (group B), $9.7 \pm 2.5 \mathrm{~cm} /$ year (group C) and $11.2 \pm 2.1$ $\mathrm{cm} /$ year (group D) ( $p=0.001$ for groups A vs. D). This effect was sustained, resulting in a height SD score improvement during the second and third years. Most treatment-emergent adverse events were mild and transient. Conclusion: In children with short stature, GH sufficiency and low IGF-1, coadministration of $\mathrm{rhGH} / \mathrm{rhlGF}-1(45 / 150 \mu \mathrm{g} / \mathrm{kg})$ significantly accelerated linear growth compared with rhGH alone, with a safety profile similar to the individual monotherapies.

(c) 2015 S. Karger AG, Basel

\begin{tabular}{ll}
\hline KARGER 125/s & $\begin{array}{l}\text { @ 2015 S. Karger AG, Basel } \\
1663-2818 / 15 / 0834-0268 \$ 39.50 / 0 \quad \text { Karger }\end{array}$ \\
$\begin{array}{l}\text { E-Mail karger@karger.com caccess } \\
\text { www.karger.com/hrp }\end{array}$ & $\begin{array}{l}\text { This is an Open Access article licensed under the terms of the } \\
\text { Creative Commons Attribution-NonCommercial 3.0 Un- } \\
\text { ported license (CC BY-NC) (www.karger.com/OA-license), } \\
\text { applicable to the online version of the article only. Distribu- } \\
\text { tion permitted for non-commercial purposes only. }\end{array}$
\end{tabular}

Philippe Backeljauw, MD, Professor of Clinical Pediatrics

Cincinnati Children's Hospital Medical Center

3333 Burnet Avenue, Room R-8544

Cincinnati, OH 45229 (USA)

E-Mail philippe.backeljauw@cchmc.org 


\section{Introduction}

Growth hormone (GH) and insulin-like growth factor-1 (IGF-1) have growth-promoting effects through both overlapping and complementary actions [1]. For normal growth to occur, optimal exposure to the actions of both GH and IGF-1 are required. In several animal models, including hypophysectomized rats and knockout mice, defects of the GH-IGF-1 axis cause severe growth failure $[2,3]$. In human IGF-1 insufficiency, due to either GH deficiency or GH insensitivity, childhood growth failure results, and, if left untreated, leads to variable degrees of short stature in adulthood $[4,5]$. Treatment with recombinant human (rh)GH for GH deficiency [6] or with rhIGF-1 for IGF-1 deficiency (IGFD) [5] improves linear growth, but does not always result in normalization of adult height. Treatment outcome is influenced by multiple factors (including genetics and nutrition), but may also be limited by the inability to adequately correct the abnormalities of the GH-IGF axis with either rhGH or rhIGF-1 monotherapy [7]. For example, in children with short stature and low IGF-1, weight-based rhGH dosing does not consistently result in serum IGF-1 normalization, and IGF-1-based dosing to reach serum IGF-1 titration targets may require three times the recommended rhGH dose $[8,9]$. In addition, with rhIGF-1 monotherapy, suppression of nocturnal GH secretion may negatively affect the growth response [10].

$\mathrm{GH}$ has specific properties that differ from those of IGF-1, such as (pre)chondrocyte differentiation and lipolysis. The effect of both hormones has been demonstrated to be additive with coadministration in rodents $[11,12]$. In addition, combined administration of rhGH and rhIGF-1 is more anabolic in calorie-restricted adults [13]. Combining rhGH with rhIGF-1 therapy to take advantage of their synergistic actions may provide greater efficacy than either rhGH or rhIGF-1 alone.

This study is the first to evaluate the potential benefit of rhGH/rhIGF-1 combination therapy in GH-sufficient children with short stature and low IGF-1, compared with a control group of children treated with rhGH monotherapy.

\section{Materials and Methods}

\section{Patients}

Patients with short stature (defined as height SD score $\leq-2.0$ for age and sex), low IGF-1 (IGF-1 SD score $\leq-1.0$ for age and sex) and $\mathrm{GH}$ sufficiency (maximum stimulated $\mathrm{GH} \geq 10 \mathrm{ng} / \mathrm{ml}$ ) were recruited from 27 US pediatric endocrinology centers. Eligible patients were treatment-naïve, prepubertal, $\geq 5$ years in age, with bone ages
(BAs) $\leq 9$ years (girls) or $\leq 11$ years (boys), BMI $\geq 5$ th percentile for age and sex, and normal screening laboratory findings. Exclusion criteria comprised the presence of identifiable syndromes, severe IGFD (height and IGF-1 SD score $\leq-3$ and stimulated GH response $\geq 10 \mathrm{ng} / \mathrm{ml}$ ), chronic illnesses that could affect treatment outcomes (e.g. active neoplasm, or congenital and acquired pituitary disease), previous or current use of growth-altering medication (e.g. rhGH, rhIGF-1, sex steroids, gonadotropin agonists), use of attention-deficit/hyperactivity disorder medication or glucocorticoids within 3 months of study entry, and allergy to study drugs.

The protocol was approved by each local institutional review board and/or by the Independent Review Consulting Inc. institutional review board (www.clinicaltrials.gov; identifier: NCT00572156). Parents or legally authorized representatives provided informed consent prior to any study-related activities.

\section{Study Design}

This was a randomized, multicenter, open-label, active treatment-controlled, parallel-group, dose-comparison, phase 2 clinical trial (3 years' duration). After successful screening, patients were randomized to 1 of 4 groups (all doses in $\mu \mathrm{g} / \mathrm{kg} /$ day): $45 \mathrm{rhGH}$ alone (group A), $45 \mathrm{rhGH}+50$ rhIGF-1 (group B), $45 \mathrm{rhGH}+100$ rhIGF-1 (group C) or 45 rhGH + 150 rhIGF-1 (group D). The study arms were stratified by age ( $\leq 9$ years) and IGF- 1 SD score $\leq-2$ in a 1:1:1:1 ratio (fig. 1). Patients received once daily (morning) s.c. injections of either $45 \mu \mathrm{g} \mathrm{rhGH} / \mathrm{kg} /$ day alone [Nutropin $\mathrm{AQ}^{\circledR}$, somatropin (rDNA) injection; Genentech Inc., South San Francisco, Calif., USA] or $45 \mu \mathrm{g} \mathrm{rhGH} / \mathrm{kg} /$ day as one injection plus 50,100 or $150 \mu \mathrm{g}$ rhIGF-1/kg/day [Increlex ${ }^{\circledR}$, mecasermin (rDNA) injection; Ipsen Biopharmaceuticals Inc., Basking Ridge, N.J., USA] as a separate s.c. injection in contralateral sites. Treatment was initiated at $50 \%$ of the assigned $\mathrm{rhGH} / \mathrm{rhIGF}-1$ dose, and increased to the full dose on treatment day 15. A dose-reduction guideline was implemented to ensure patient safety in light of the unknown effect of prolonged exposure to high IGF-1 concentrations. At the discretion of the investigator and after consultation with the study sponsor, patients experiencing a near-peak serum IGF-1 SD score $>+4$ on $\geq 2$ occasions were instructed to take a reduced dose at the same rhGHto-rhIGF-1 ratio. Up to two dose reductions were allowed.

The primary endpoint was first-year height velocity (HV). Secondary endpoints included HV during the second and third years; change in height SD score (years 1-3); change in BA; change in BMI; change in GH, IGF-1 and IGF-binding protein 3 (IGFBP-3), and safety monitoring. Height SD score was calculated using the National Center for Health Statistics 2000 data as provided by the Centers for Disease Control and Prevention [14].

After screening, patients were evaluated at baseline and weeks $2,4,13,26,39,52,68,86,104,120,138$ and 156. At each visit, patients had a physical examination (including vital signs, height, weight and fundi), and adverse events were reviewed. Treatment compliance was monitored using patients' drug administration diaries, study drug dispensing records and measurement of serum GH, IGF-1 and IGFBP-3 at each visit.

\section{Bone Age}

To determine the BA, left hand and wrist radiographs were obtained at screening and thereafter annually (years 1-3), and evaluated centrally (LifeSpan Research Inc., Kettering, Ohio, USA). Radiographs performed up to 6 months prior to screening could also be used in place of the screening radiograph. 


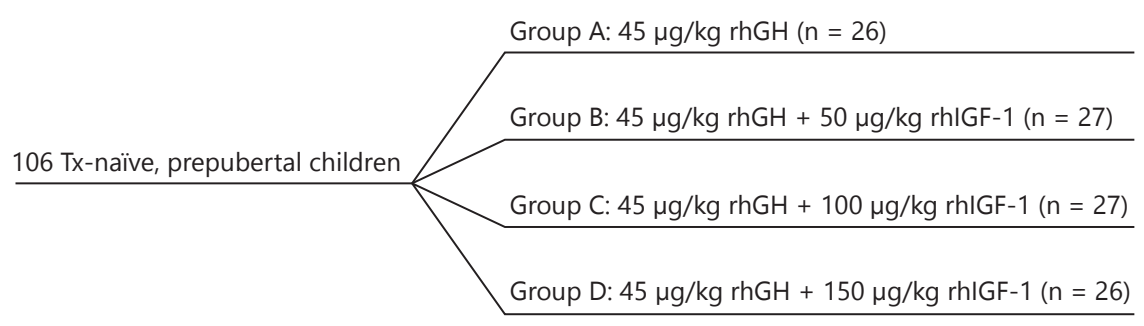

Fig. 1. Study design. Recruited patients were randomized using a central randomization procedure. Study arms were randomized in a 1:1:1:1 ratio, and stratified by age $\leq 9$ years and IGF-1 SD score $\leq-2$ at screening. rhGH [Nutropin AQ; somatropin (rDNA) injection] \pm rhIGF-1 [Increlex; mecasermin (rDNA) injection] were

\section{Laboratory Examinations}

Before randomization, each patient underwent $\mathrm{GH}$ stimulation testing after an overnight fast to confirm GH sufficiency. Following the baseline sample, patients received i.v. $0.5 \mathrm{~g} / \mathrm{kg}$ arginine $10 \%$ solution (max. $30 \mathrm{~g}$ in a $30-\mathrm{min}$ infusion) and oral clonidine [0.1 $\mathrm{mg}$ for patients $<50 \mathrm{lbs}(22.7 \mathrm{~kg}$ ) or $0.2 \mathrm{mg}$ for patients $\geq 50 \mathrm{lbs}]$. A participating site could adapt this protocol according to local practice (using alternative GH secretagogues, doses or timing of administration) following written approval from the study sponsor. GH, IGF-1 and IGFBP-3 levels were determined at each study visit using the Esoterix immunoassay (Esoterix, Calabasas Hills, Calif., USA). IGF-1 and IGFBP-3 SD scores were computed using normative data. A single IGF-1 concentration, measured on a sample obtained at the first study visit, was used to determine the baseline IGF-1 concentration. Anti-IGF-1 antibodies were measured (Ipsen Pharma SA, Barcelona, Spain) on treatment day 1 and, thereafter, annually up to 3 years following initiation of treatment. Safety laboratory examinations, which included routine blood counts, serum chemistries, thyroid function, urinalysis, fasting lipids, glucose, insulin, C-peptide and glycosylated hemoglobin, were analyzed in a central laboratory (Esoterix).

\section{Statistical Analyses}

A sample size of 25 patients per group was estimated to provide $96 \%$ power, using one-sided testing at $\alpha=0.0173$ in each of three two-sample t tests. We assumed that 23 patients would complete the first year of study and that the mean difference for first-year $\mathrm{HV}$ between the rhGH and $\mathrm{rhGH} / \mathrm{rhIGF}-1$ therapies would be 2.0 $\mathrm{cm} /$ year, whereas the within-treatment arm SD would be $1.6 \mathrm{~cm} /$ year [9]. The primary efficacy analysis used a modified intentionto-treat (mITT) population, comprising all randomized patients who had at least one postbaseline height measurement. Missing height values at the end of year 1 were imputed (i.e. substituted by the last observed value) in this analysis (see below). The safety population comprised all randomized patients.

Analysis of covariance (ANCOVA) was used to compare the first-year HV for the three coadministration groups (B-D) with the $\mathrm{HV}$ for group $\mathrm{A}$, using randomization strata defined by baseline age and IGF-1 SD score as covariates. A similar analysis was also used to compare $\mathrm{HV}$ between groups during the second and administered s.c. once daily in the morning as separate injections at contralateral sites. In group A, 1 patient was subsequently found to be $\mathrm{GH}$ deficient following randomization and initiation of study treatment (rhGH alone), and was therefore withdrawn from the study and excluded from mITT. Tx $=$ Treatment.

third year for the mITT population. Height SD score was imputed for years 1-3 only if a patient had at least one height value recorded in the specified year. HVs were imputed assuming no change in height SD score after the last measurement. All imputation (i.e. substitution for missing values) was done using the last observation carried forward method.

The ANCOVAs were also done on the completer populations (patients who completed each year of the study). Changes in height SD score within the mITT and completer populations were analyzed with ANCOVA using randomization strata defined by baseline age and IGF-1 SD score as covariates. A similar analysis was also done using subgroups of pubertal patients within the completer populations. All p values were two-sided.

Post hoc ANCOVA on Roche-Wainer-Thissen (RWT) predicted adult height $(\mathrm{PAH})$ was performed adjusting for baseline age and IGF-1 SD score and using the multiple Dunnett adjustment. Student's t test was performed to analyze the difference in BMI between baseline and the end of the study.

\section{Results}

The study was conducted between January 2008 and March 2012, and 106 patients were randomized to treatment. One patient initially randomized to receive $\mathrm{rhGH}$ monotherapy was subsequently found to be GH deficient and was removed from the study. The enrollment characteristics were similar for the four subgroups (table 1). The majority of patients were male (80.2\%). Overall mean \pm SD age was $8.8 \pm 2.1$ years, height SD score was $-2.5 \pm 0.4$, IGF-1 SD score was $-1.9 \pm 0.6$, BA was $7.3 \pm$ 1.9 years and BMI SD score was $-0.4 \pm 0.7$. A total of 22 patients $(n=6,3,5$ and 8 in groups $A, B, C$ and $D$, respectively) were deemed to have entered puberty (breast/testes Tanner stage 2) during the first year of the study, at ages ranging from 9.3 to 14.4 years in males and 8.7 to 
Table 1. Enrollment characteristics by dosing group

\begin{tabular}{|c|c|c|c|c|}
\hline & $\begin{array}{l}\text { Group A } \\
(n=26)\end{array}$ & $\begin{array}{l}\text { Group B } \\
(\mathrm{n}=27)\end{array}$ & $\begin{array}{l}\text { Group C } \\
(\mathrm{n}=27)\end{array}$ & $\begin{array}{l}\text { Group D } \\
(\mathrm{n}=26)\end{array}$ \\
\hline Female, \% & 19 & 19 & 26 & 15 \\
\hline Chronological age, years & $9.2 \pm 2.0$ & $8.4 \pm 2.0$ & $9.0 \pm 2.2$ & $8.8 \pm 2.3$ \\
\hline Imputed BA, years & $7.6 \pm 1.7$ & $7.2 \pm 1.8$ & $7.2 \pm 2.0$ & $7.3 \pm 2.0$ \\
\hline Height, $\mathrm{cm}$ & $119.1 \pm 10.0$ & $115.8 \pm 9.5$ & $117.7 \pm 11.5$ & $116.7 \pm 11.8$ \\
\hline Height SD score & $-2.5 \pm 0.5$ & $-2.5 \pm 0.4$ & $-2.6 \pm 0.4$ & $-2.6 \pm 0.4$ \\
\hline Mother's height, $\mathrm{cm}$ & $157 \pm 5$ & $157 \pm 5$ & $157 \pm 6$ & $159 \pm 7$ \\
\hline Father's height, cm & $172 \pm 4$ & $169 \pm 5$ & $173 \pm 7$ & $172 \pm 6$ \\
\hline Weight SD score & $-2.0 \pm 0.7$ & $-2.1 \pm 0.6$ & $-2.0 \pm 0.7$ & $-2.2 \pm 0.9$ \\
\hline BMI SD score & $-0.3 \pm 0.7$ & $-0.5 \pm 0.7$ & $-0.4 \pm 0.7$ & $-0.5 \pm 0.8$ \\
\hline IGF-1 SD score & $-1.8 \pm 0.5$ & $-2.0 \pm 0.7$ & $-1.8 \pm 0.6$ & $-2.0 \pm 0.6$ \\
\hline IGFBP-3 SD score & $-1.1 \pm 0.7$ & $-1.2 \pm 0.9$ & $-1.0 \pm 0.8$ & $-1.3 \pm 0.8$ \\
\hline Maximum stimulated $\mathrm{GH}, \mathrm{ng} / \mathrm{ml}$ & $17.9 \pm 8.9$ & $18.2 \pm 8.4$ & $19.5 \pm 6.3$ & $20.1 \pm 8.4$ \\
\hline
\end{tabular}

Values are means \pm SD. Unless specified: group $\mathrm{A}=45 \mu \mathrm{g} / \mathrm{kg}$ rhGH alone; group B $=45 \mu \mathrm{g} / \mathrm{kg} \mathrm{rhGH}+50 \mu \mathrm{g} /$ $\mathrm{kg}$ rhIGF-1; group C $=45 \mu \mathrm{g} / \mathrm{kg}$ rhGH $+100 \mu \mathrm{g} / \mathrm{kg}$ rhIGF-1; group D $=45 \mu \mathrm{g} / \mathrm{kg} \mathrm{rhGH}+150 \mu \mathrm{g} / \mathrm{kg}$ rhIGF- 1 .

12.9 years in females. Only one patient reached Tanner stage 3 in the first year of the study, a male in group A at age 12.8 years.

Assessment of compliance for both rhGH and rhIGF-1 injections in all groups using patient diaries demonstrated that $75 \%$ of patients missed fewer than $13 \%$ of their doses. The total cumulative average rhIGF- 1 dose (mean \pm SD in $\mu \mathrm{g} / \mathrm{kg}$ ) for completers was $48.7 \pm 2.2$ (group B, target dose: $50 \mu \mathrm{g} / \mathrm{kg}$ ), $87.8 \pm 14.8$ (group C, target dose: 100 $\mu \mathrm{g} / \mathrm{kg}$ ) and $132.8 \pm 20.2$ (group D, target dose: $150 \mu \mathrm{g} / \mathrm{kg}$ ). The total cumulative average rhGH dose (mean \pm SD in $\mu \mathrm{g} / \mathrm{kg}$ ) was $44.1 \pm 2.5,44.1 \pm 1.2,39.5 \pm 6.7$ and $40.0 \pm 6.0$ for groups A-D, respectively (target dose: $45 \mu \mathrm{g} / \mathrm{kg}$ ). The mITT population consisted of 105 patients in year 1, 94 in year 2 and 85 in year 3.

\section{Primary Efficacy Endpoint: First-Year HV}

The first-year HV within the mITT population was $9.3 \pm 1.7 \mathrm{~cm} /$ year in group A $(\mathrm{n}=25), 10.1 \pm 1.3 \mathrm{~cm} /$ year in group $B(\mathrm{n}=27), 9.7 \pm 2.5 \mathrm{~cm} /$ year in group $\mathrm{C}(\mathrm{n}=$ 27) and $11.2 \pm 2.1 \mathrm{~cm} /$ year in group $\mathrm{D}(\mathrm{n}=26$; (fig. 2; online suppl. fig. 1; for all online suppl. material, see www.karger.com/doi/10.1159/000371799). The difference between groups A and D was statistically significant $(\mathrm{p}=0.001)$. ANCOVA of patients completing 1 year of therapy yielded the same result. The statistical significance observed in the primary analysis was not affected by pubertal status, BA or presence/absence of anti-IGF-1 antibodies.

rhGH/rhIGF-1 Therapy for Short Stature

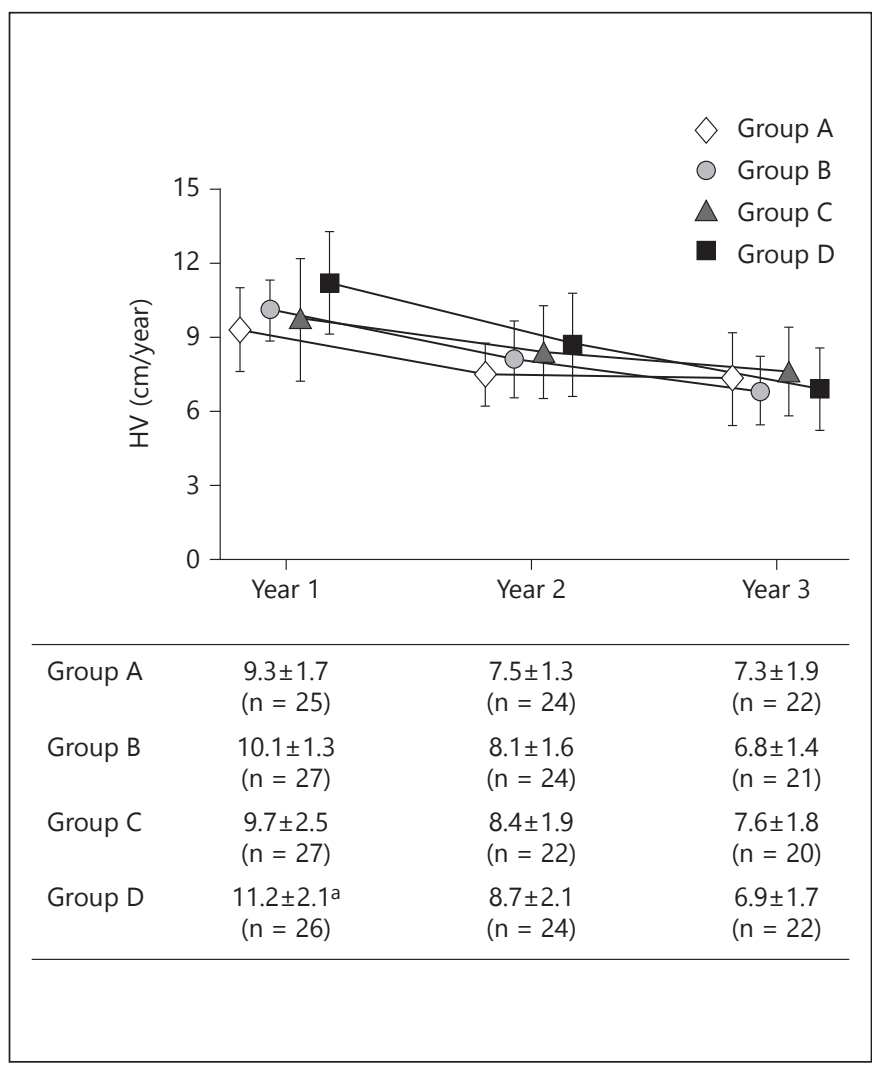

Fig. 2. Evolution of height velocity (mean $\pm S D$, mITT population). Group $\mathrm{A}=45 \mu \mathrm{g} / \mathrm{kg}$ rhGH alone; group $\mathrm{B}=45 \mu \mathrm{g} / \mathrm{kg}$ rhGH +50 $\mu \mathrm{g} / \mathrm{kg}$ rhIGF-1; group $\mathrm{C}=45 \mu \mathrm{g} / \mathrm{kg} \mathrm{rhGH}+100 \mu \mathrm{g} / \mathrm{kg}$ rhIGF-1; group $\mathrm{D}=45 \mu \mathrm{g} / \mathrm{kg} \mathrm{rhGH}+150 \mu \mathrm{g} / \mathrm{kg}$ rhIGF-1. ${ }^{\mathrm{a}} \mathrm{p}=0.001$ vs. rhGH alone, Dunnett's adjustment. 


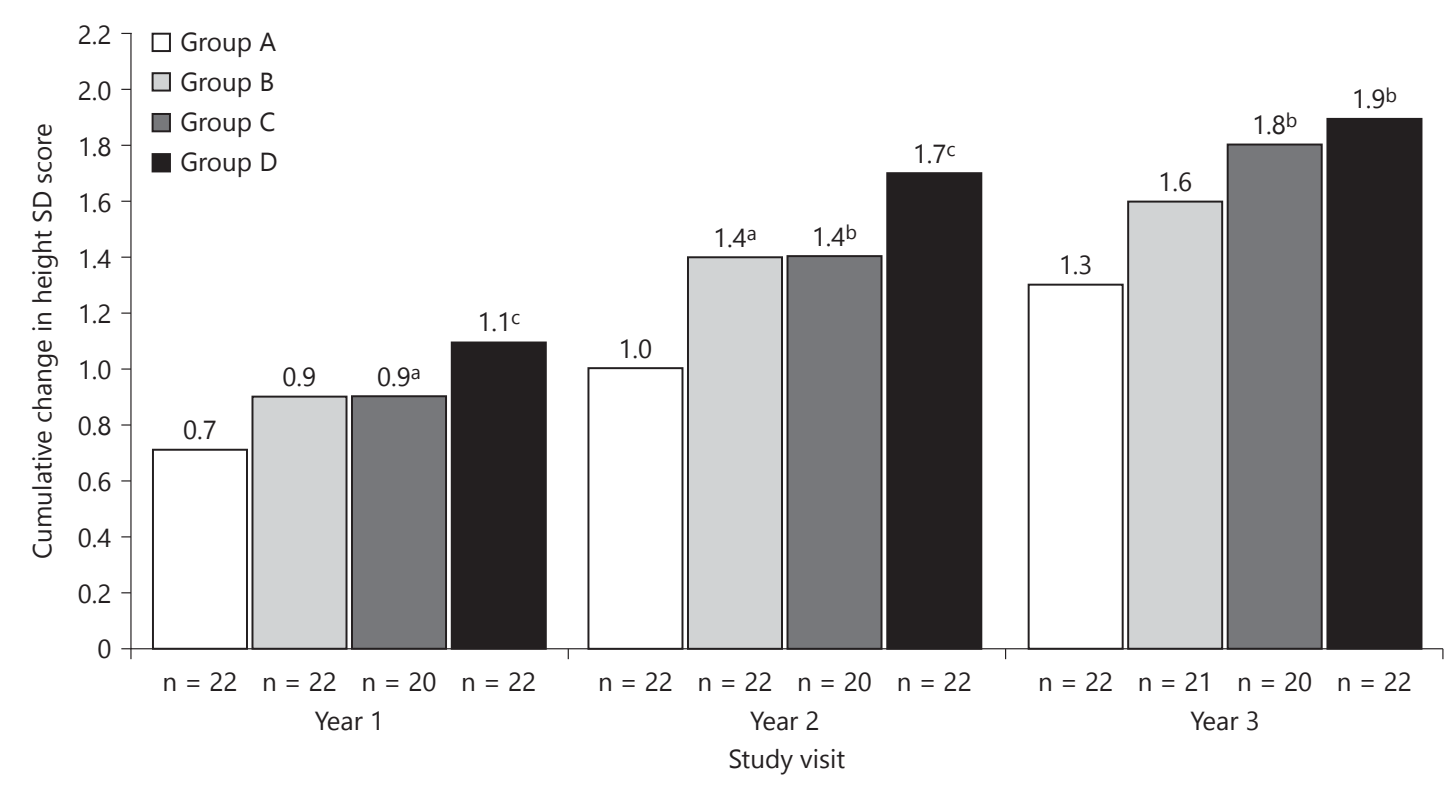

Fig. 3. Change in cumulative height SD score (mITT population). Group $A=45 \mu \mathrm{g} / \mathrm{kg}$ rhGH alone; group $B=$ $45 \mu \mathrm{g} / \mathrm{kg} \mathrm{rhGH}+50 \mu \mathrm{g} / \mathrm{kg}$ rhIGF-1; group C $=45 \mu \mathrm{g} / \mathrm{kg} \mathrm{rhGH}+100 \mu \mathrm{g} / \mathrm{kg}$ rhIGF-1; group D = $45 \mu \mathrm{g} / \mathrm{kg} \mathrm{rhGH}+$ $150 \mu \mathrm{g} / \mathrm{kg}$ rhIGF-1. ${ }^{\mathrm{a}} \mathrm{p}<0.05 ;{ }^{\mathrm{b}} \mathrm{p}<0.01 ;{ }^{\mathrm{c}} \mathrm{p}<0.0001$; vs. rhGH alone, Dunnett's adjustment.

Secondary Efficacy Endpoints: HV during the Second and Third Years of Treatment, and Cumulative Change in Height SD Score during the First, Second and Third Years of Treatment

During the second year of therapy, HV was greater in the coadministration groups than in group A, although these differences were not statistically significant (fig. 2). Third-year HV ranged from 6.8 (group B) to 7.6 (group C) with higher HV observed in group A compared with groups B and D.

The cumulative $\Delta$ height SD score over 3 years for the mITT population is shown in figure 3. The first-year $\Delta$ height SD scores (mean $\pm \mathrm{SD}, \mathrm{cm}$ /year) were: group $\mathrm{A}$, $0.7 \pm 0.3(n=22)$; group $B, 0.9 \pm 0.2(n=22)$; group $C$, $0.9 \pm 0.4(\mathrm{n}=20)$, and group $\mathrm{D}, 1.1 \pm 0.3(\mathrm{n}=22)$. The difference in $\Delta$ height SD score was statistically significant for the highest two dose combination groups (group C vs. group A: $p<0.05$; group D vs. group A: $p<0.0001$ ). The effect seen in group $\mathrm{D}$ on cumulative change in height SD score compared with group A was sustained during the second and third years of therapy. After 3 years the cumulative height SD score gains were 1.3, 1.6, 1.8 and 1.9 in groups A-D, respectively, with significant differences observed between groups $\mathrm{C}$ and $\mathrm{D}$ versus group $\mathrm{A}$ $(\mathrm{p}=0.008$ and 0.002$)$.

\section{Skeletal Maturation}

Baseline BA was delayed in relation to chronological age and increased in all treatment groups. The change in BA (years, \pm SD) from baseline to year 1 was of a similar magnitude in all treatment groups: group A, $1.2 \pm 0.5(\mathrm{n}=$ $24)$; group $B, 1.3 \pm 0.5(\mathrm{n}=25)$; group $\mathrm{C}, 1.2 \pm 0.4(\mathrm{n}=$ $22)$, and group $\mathrm{D}, 1.3 \pm 0.6(\mathrm{n}=25)$. The advancement in $\mathrm{BA}$ by year 3 was comparable in the coadministration groups versus the rhGH alone group: group $\mathrm{B}, 4.0 \pm 0.6$ $(\mathrm{n}=19)$; group $\mathrm{C}, 4.0 \pm 1.1(\mathrm{n}=19)$, and group $\mathrm{D}, 4.0 \pm$ $0.9(n=20)$, versus group $A, 3.8 \pm 1.0(n=21)$. These data indicate that increased growth (in the combination groups vs. the $\mathrm{GH}$ alone group) was not accompanied by undue skeletal maturation.

\section{Predicted Adult Height}

The RWT method for PAH [15], refined by Khamis and Guo [16], and adjusted for growth after age 18 years according to Roche and Davila [17], was calculated at baseline and for each year of therapy for all patients. All four treatment groups demonstrated an improvement in RWT-PAH SD score at year 1, with higher changes (mean $\pm \mathrm{SD}$ ) observed in the three coadministration groups: group A, $0.53 \pm 0.36(\mathrm{n}=24)$; group $\mathrm{B}, 0.63 \pm 0.21$ $(\mathrm{n}=25)$; group $\mathrm{C}, 0.67 \pm 0.37(\mathrm{n}=22)$, and group $\mathrm{D}$, 
$0.76 \pm 0.31(\mathrm{n}=25)$. In a post hoc analysis, a statistically significant difference $(\mathrm{p}<0.05)$ was met when comparing group A versus group D. The RWT-PAH improvement was sustained during the second and third years of treatment and remained higher in the three coadministration groups. The greatest increase in RWT-PAH SD score was observed during the first year, in line with the catch-up $\mathrm{HV}$ observed in that year. Details are provided in online supplementary table 1 .

\section{Total Change in BMI}

Baseline BMI SD score was not as low as the height SD score $(-0.4 \pm 0.7$ vs. $-2.5 \pm 0.4)$. A Student's t test was performed to analyze whether there was a change in BMI between baseline and the end of study. The results demonstrated an increase in BMI SD score at the end of study compared with baseline ( $\mathrm{p}<0.005$ in all four groups). This was most noticeable in the coadministration groups: mean change in BMI SD score from baseline was 0.45 , 0.42 and 0.64 , respectively, in groups B-D (vs. 0.34 in group A).

\section{Changes in Serum Concentrations of GH, IGF-1,}

IGFBP, Acid-Labile Subunit, and GH-Binding Protein

Trough serum $\mathrm{GH}$ and $\mathrm{GH}$-binding protein values were highly variable in all treatment arms. Mean trough IGF-1 increased with therapy, and a bigger increase was observed in the coadministration groups. There was no evidence of a clear dose effect or of a correlation between trough IGF-1 and HV. The IGF-1 SD score for the mITT population is shown in figure 4a. For near-peak IGF-1 SD score values (i.e. those taken $2-4 \mathrm{~h}$ after study injections), there was an increase between weeks 39 and 120 for all groups. However, IGF-1 decreased after week 120 in the coadministration groups, possibly due to discretionary dose reductions done if IGF- 1 SD score $>+4$. The mean near-peak IGF-1 SD score was at least +2.5 SD between weeks 39 and 120 in both groups $C$ and D. The mean trough IGF-1 in group A at 1 month was $207.9 \mathrm{ng} /$ $\mathrm{ml}$, which was similar to the mean trough IGF-1 in the coadministration groups (206.5, 205.3 and $213.3 \mathrm{ng} / \mathrm{ml}$ for groups B-D, respectively), with SDs ranging from 84.4 to 119.0 within each of the four groups. Mean trough IGF-1 values during subsequent years tended to be higher in the coadministration groups (groups B-D) than in group A (year 1: 327, 398 and 296 vs. $278 \mathrm{ng} / \mathrm{ml}$; year 2: 427, 539 and 466 vs. $312 \mathrm{ng} / \mathrm{ml}$; year 3: 405, 462 and 441 vs. $335 \mathrm{ng} / \mathrm{ml}$, respectively). Mean trough IGF-1 SD scores during these subsequent years were therefore: year $1=1.12 \pm 1.06,1.42 \pm 1.08$ and $0.70 \pm 1.12$ (groups

rhGH/rhIGF-1 Therapy for Short Stature
B-D) versus $0.37 \pm 0.78$ (group A); year $2=1.67 \pm 1.42$, $2.26 \pm 0.99$ and $1.85 \pm 1.19$ (groups $\mathrm{B}-\mathrm{D}$ ) versus $0.50 \pm$ 0.64 (group $\mathrm{A}$ ), and year $3=1.30 \pm 1.26,1.54 \pm 1.07$ and $1.41 \pm 1.44$ (groups B-D) versus $0.52 \pm 0.81$ (group A). The mean trough IGF-1 SD score remained within the normal range in years 1-3 in all groups, but was slightly higher than $+2 \mathrm{SD}(+2.26)$ in group $\mathrm{C}$ and close to $+2 \mathrm{SD}$ $(+1.85)$ in group $\mathrm{D}$. The number of patients with a trough IGF-1 SD score $\geq+2$ is shown in online supplementary table 2 .

The IGFBP-3 SD score for the mITT population is shown in figure $4 \mathrm{~b}$. At 1 month of therapy, trough IGFBP-3 was 2,852, 2,469, 2,346 and $2,427 \mathrm{ng} / \mathrm{ml}$ for groups A-D, respectively, with SDs varying between 384 and $908 \mathrm{ng} / \mathrm{ml}$ across the groups. During subsequent years, IGFBP-3 increased in all groups with the same magnitude and remained normal. Mean trough IGFBP-3 ranged from $2,624 \mathrm{ng} / \mathrm{ml}$ or $-0.38 \mathrm{SD}$ score (group D) to $2,954 \mathrm{ng} / \mathrm{ml}$ or $-0.07 \mathrm{SD}$ score (group A) at year $1,2,755$ $\mathrm{ng} / \mathrm{ml}$ or -0.35 SD score (group D) to $3,060 \mathrm{ng} / \mathrm{ml}$ or 0.05 SD score (group C) at year 2, and 3,260 ng/ml or $0.26 \mathrm{SD}$ score (group D) to $3,432 \mathrm{ng} / \mathrm{ml}$ or $0.56 \mathrm{SD}$ score (group B) at year 3. The acid-labile subunit (ALS) showed a similar upward trend in all treatment groups: mean trough ALS ranged from $11.5 \mathrm{mg} / \mathrm{l}$ (group D) to $16.0 \mathrm{mg} / \mathrm{l}$ (group A) at year $1,13.7 \mathrm{mg} / \mathrm{l}$ (group D) to $15.7 \mathrm{mg} / \mathrm{l}$ (group C) at year 2 and $11.2 \mathrm{mg} / \mathrm{l}$ (group D) to $13.7 \mathrm{mg} / \mathrm{l}$ (group A) at year 3. IGFBP-1 declined with the same average magnitude in all groups and all values remained in the normal range throughout (data not shown).

\section{Safety}

Each patient reported at least one treatment-emergent adverse event (TEAE) over the course of the study (table 2). The number of TEAEs was 374, 406, 392 and 513 in groups $\mathrm{A}-\mathrm{D}$, respectively, with these treatment differences mostly being driven by the variation of mild-tomoderate adverse events. The number of severe adverse events was similar in each of the groups. Most events were transient and not considered drug related: $>80 \%$ of TEAEs within each group were of mild severity. Ten patients withdrew from the study because of a TEAE (table 2). In 6 of these cases (patients with injection site pain (2 patients), alopecia, neck pain, urticaria and drug hypersensitivity), the events were considered related to treatment. Five of these related events were of moderate intensity and one was of mild intensity. One of the events considered to be unrelated to study treatment (Evan's syndrome) was classified by the investigator as a serious adverse event. Previous studies have identified several ad- 
Fig. 4. IGF-1 SD score (a) and IGFBP-3 SD score (b) for the mITT population during the study. Group $\mathrm{A}=45 \mu \mathrm{g} / \mathrm{kg}$ rhGH alone; group $\mathrm{B}=45 \mu \mathrm{g} / \mathrm{kg}$ rhGH $+50 \mu \mathrm{g} / \mathrm{kg}$ rhIGF-1; group $\mathrm{C}=45 \mu \mathrm{g} / \mathrm{kg} \mathrm{rhGH}+100 \mu \mathrm{g} / \mathrm{kg}$ rhIGF-1; group D = $45 \mu \mathrm{g} / \mathrm{kg} \mathrm{rhGH}+150 \mu \mathrm{g} /$ $\mathrm{kg}$ rhIGF-1. Large symbols represent mean values. Near-peak measurements: screening; day 15; weeks 39, 68 and 120; trough measurements: weeks 52, 104 and 156.

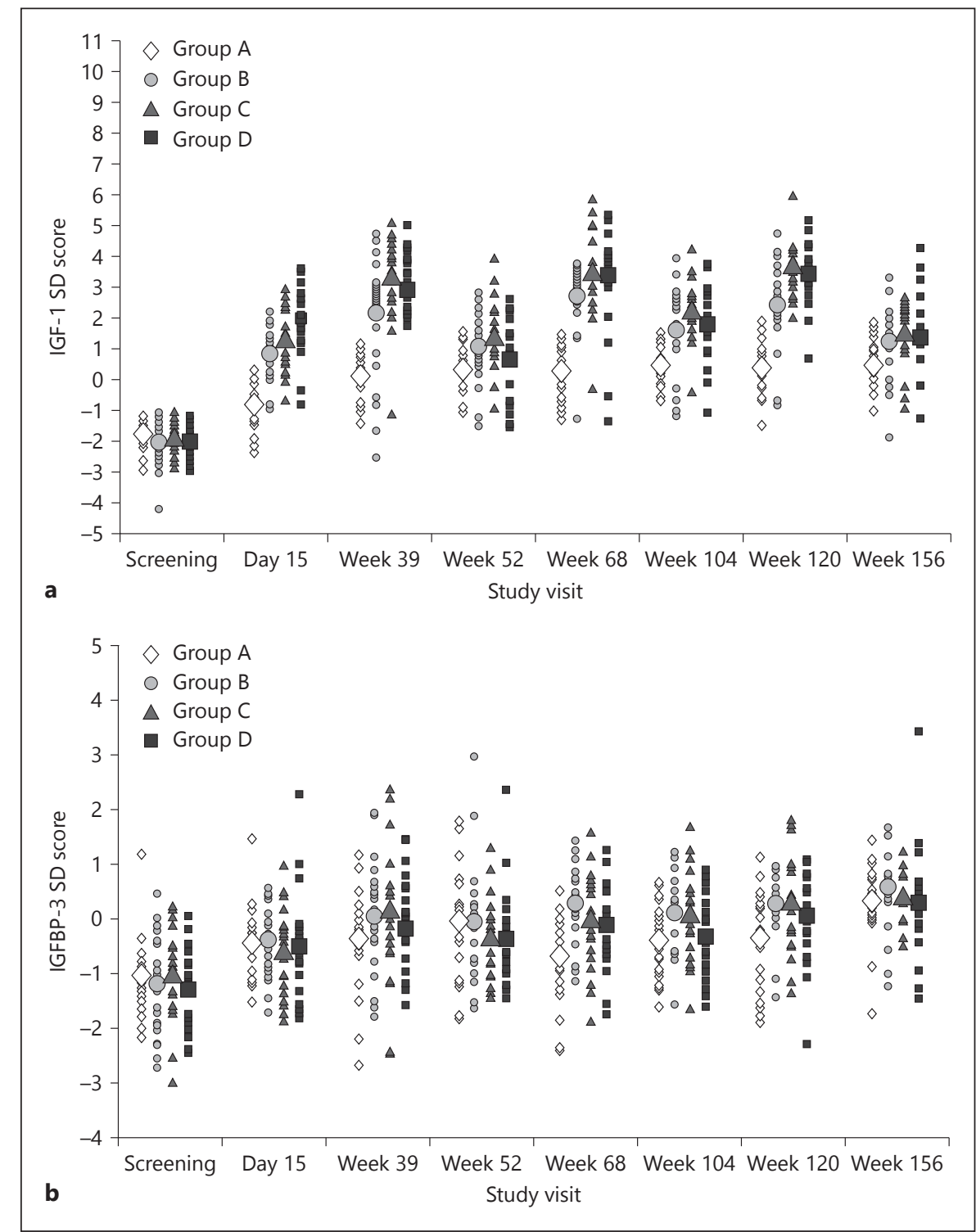

verse events of special interest that may be associated with rhIGF-1 exposure and these were monitored in the study.

Headache was reported with the highest incidence: in $14 / 26$ patients (54\%) with 40 occurrences in group A, in $14 / 27$ patients (52\%) with 43 occurrences in group B, in $17 / 27$ patients (63\%) with 39 occurrences in group $C$ and in 18/26 (69\%) with 50 occurrences in group D. Headaches were reported earlier by patients treated with coadministration therapy (median 19 days; $\mathrm{n}=80$ ) than with rhGH monotherapy (median 73 days; $n=26$ ). The percentage of patients experiencing a first headache increased with increasing rhIGF-1 dose in the earlier stage of the study (i.e. at month $8: 38,44,48$ and $62 \%$ of the patients in groups A-D, respectively, had experienced their first headache). This trend was less apparent in later phases of the study (after month 16). Most headaches were not severe, were transient in nature, and were not a cause of refusal to treat.

Of the adverse events of special interest, injection site lipohypertrophy (a known insulin-like effect of rhIGF-1 therapy $[5,7]$ ) was reported in 16 patients, all receiving coadministration therapy: $6 / 27,7 / 27$ and $3 / 26$ in groups $\mathrm{B}-\mathrm{D}$, respectively. Tonsil or adenoid hypertrophy was reported at a greater frequency in group A $(4 / 26 ; 15 \%)$ compared with the combination groups $(4 / 80 ; 5 \%)$. Vomiting occurred in $9 / 26(35 \%)$ of patients in the $\mathrm{rhGH}$ alone 
Table 2. Summary of treatment exposure and TEAEs, and number and percentage of patients reporting TEAEs of special interest with the number of occurrences (safety population)

\begin{tabular}{|c|c|c|c|c|}
\hline & $\begin{array}{l}\text { Group A } \\
(n=26)\end{array}$ & $\begin{array}{l}\text { Group B } \\
(\mathrm{n}=27)\end{array}$ & $\begin{array}{l}\text { Group C } \\
(\mathrm{n}=27)\end{array}$ & $\begin{array}{l}\text { Group D } \\
(n=26)\end{array}$ \\
\hline \multicolumn{5}{|l|}{ Treatment exposure } \\
\hline Patient-years, $\mathrm{n}$ & 76 & 75 & 72 & 77 \\
\hline \multicolumn{5}{|l|}{ TEAEs } \\
\hline Number of events & 374 & 406 & 392 & 513 \\
\hline Patients with TEAEs of special interest ${ }^{\mathrm{a}}, \mathrm{n}(\%)$ [occurrences] & $22(85)$ & $21(78)$ & $25(93)$ & $26(100)$ \\
\hline Headache & $14(54)[40]$ & $14(52)[43]$ & $17(63)[39]$ & $18(69)[50]$ \\
\hline Vomiting & $9(35)[17]$ & 5 (19) [6] & $6(22)[12]$ & $12(46)[19]$ \\
\hline Otitis media & $4(15)[4]$ & $5(19)[7]$ & $3(11)[5]$ & $9(35)[19]$ \\
\hline Hypoglycemia/blood glucose decreased & $2(8)[3]$ & 0 & 0 & $7(27)[8]$ \\
\hline Arthralgia & $7(27)[8]$ & $4(15)[7]$ & $5(19)[5]$ & $6(23)[12]$ \\
\hline Hair texture abnormal & 0 & $1(4)[1]$ & $2(7)[2]$ & $1(4)[1]$ \\
\hline $\mathrm{ICH} /$ papilledema $^{\mathrm{f}}$ & 0 & 0 & $1(4)[1]$ & $1(4)[1]$ \\
\hline Lymphadenopathy & $4(15)[7]$ & $1(4)[1]$ & $3(11)[3]$ & $1(4)[1]$ \\
\hline Myalgia & $1(4)[2]$ & $2(7)[4]$ & $1(4)[1]$ & $1(4)[1]$ \\
\hline Tonsil and/or adenoid hypertrophy & $4(15)[4]$ & $2(7)[3]$ & $1(4)[1]$ & $1(4)[1]$ \\
\hline Snoring & 0 & $1(4)[1]$ & $1(4)[1]$ & 0 \\
\hline
\end{tabular}

Group $\mathrm{A}=45 \mu \mathrm{g} / \mathrm{kg}$ rhGH alone; group $\mathrm{B}=45 \mu \mathrm{g} / \mathrm{kg} \mathrm{rhGH}+50$ $\mu \mathrm{g} / \mathrm{kg}$ rhIGF-1; group C $=45 \mu \mathrm{g} / \mathrm{kg} \mathrm{rhGH}+100 \mu \mathrm{g} / \mathrm{kg}$ rhIGF-1; group $\mathrm{D}=45 \mu \mathrm{g} / \mathrm{kg} \mathrm{rhGH}+150 \mu \mathrm{g} / \mathrm{kg}$ rhIGF-1. ${ }^{\mathrm{a}}$ Number of patients with one or more events. ${ }^{\mathrm{b}}$ Injection site pain (treatment related, $\mathrm{n}=2$ ), aggression (not related, $\mathrm{n}=1$ ). ${ }^{\mathrm{c}}$ Evan's syndrome ( multaneous or sequential occurrence of Coombs-positive hemolytic anemia and immune thrombocytopenia without known etiology) in patient with a prior medical history of acute autoimmune hemolytic anemia (not related, $\mathrm{n}=1$ ). ${ }^{\mathrm{d}}$ Urticaria (related, $\mathrm{n}=1$ ), alopecia (related, $\mathrm{n}=1$ ), attention deficit/hyperactivity disorder (not related, $\mathrm{n}=1$ ), neck pain (related, $\mathrm{n}=1$ ), drug hypersensitivity (related, $\mathrm{n}=$ 1). ${ }^{\mathrm{e}}$ Fear of needles (not related, $\mathrm{n}=1$ ). ${ }^{\mathrm{f}}$ Single reported case of papilledema was considered by sponsor to be indicative of $\mathrm{ICH}$; however, confirmatory lumbar puncture was refused. group, and in 23/80 (29\%) of those receiving coadministration therapy, but the incidence of vomiting was higher in group D than in all other groups (12/26; 46\%). Vomiting was not always associated with headaches (in most patients it was not) or hypoglycemia. It occurred with a variety of other reported adverse events (e.g. influenza, gastroenteritis). There were 11 occurrences of hypoglycemia in 9 patients (reported with or without blood measurements). Two (out of 26) patients were from group A, and 7/27 were from group D; all but one were mild episodes. In 3 patients, hypoglycemia resolved spontaneously, while in 3 other patients it resolved following unspecified treatment (most likely food and/or juice). No information on treatment was reported for the remaining 3 patients. None required dose reduction. Two patients (8\%) experienced urticaria in the rhGH alone group, compared with 7 patients (9\%) in the combination groups (table 2; online suppl. fig. 2).

Five patients experienced serious adverse events during the study. In 2 of the patients, the event was considered 'related to treatment' by the investigator. The first patient, an 11-year-old male, had been randomized to group $\mathrm{D}$. He developed papilledema of moderate intensity approximately 6 weeks after treatment start. Magnetic resonance imaging (MRI) of the head was normal. Treatment was suspended for 70 days, before being restarted at a reduced dose of $33.75 \mu \mathrm{g} / \mathrm{kg} /$ day $\mathrm{rhGH}+125.5$ $\mu \mathrm{g} / \mathrm{kg} /$ day rhIGF-1; a further increase to the initial dose 12 weeks later did not result in recurrence of papilledema. This patient subsequently had IGF-1 SD scores $>+2$ on day 234 (approx. 7 weeks after the dose increase), as well as on days 597 and 729 . The first two of these measure- 
ments were unscheduled and it is not known whether they were peak or trough measurements, and the last value was a trough measurement. The doses of study drugs were reduced on day 613 as a result of elevated peak IGF1 values. This patient's presentation was indicative of intracranial hypertension (ICH), but a confirmatory lumbar puncture was refused by the family. The second patient was a 7.5-year-old female who had been randomized to group C. After approximately 6 weeks she developed ICH and was hospitalized for head MRI and confirmatory lumbar puncture. Treatment was suspended and the ICH resolved after 14 days. Treatment was then re-started at a lower dose $(33 \mu \mathrm{g} / \mathrm{kg} /$ day $\mathrm{rhGH}+75 \mu \mathrm{g} / \mathrm{kg} / \mathrm{day}$ rhIGF-1) on day 133 without recurrence of the ICH. IGF1 SD score was elevated $(>+2)$ in this patient on the day of the onset of ICH and approximately 11 weeks later (day 133). However, both of these assessments were unscheduled and it is not known whether they were peak or trough measurements. In the 3 remaining patients the serious adverse events were considered to be unrelated to treatment by the investigator and comprised a fractured arm and viral gastroenteritis in 1 patient each, and, in a single patient, Evan's syndrome, with thrombocytopenia, viral infection and hematuria.

\section{Additional Laboratory Evaluation}

No new safety signals were identified upon review of the laboratory data. Mean glycosylated hemoglobin increased slightly but remained normal in all groups. At year 3, mean percent glycosylated hemoglobin increase from day 1 was 0.6 for group A $(n=20), 0.5$ for group B $(\mathrm{n}=19), 0.5$ for group $\mathrm{C}(\mathrm{n}=17)$ and 0.7 for group $\mathrm{D}(\mathrm{n}=$ 19). Over the 3 years of the trial, elevations in glycosylated hemoglobin (above the normal range) were reported in 18 patients (group A: 8, group B: 1, group C: 4 and group D: 5). Mean blood glucose was normal throughout the study. No long-term effect of treatment on total, highand low-density lipoprotein cholesterol or triglycerides was observed. There was an initial mild and transient rise of alanine aminotransferase and aspartate aminotransferase (a known effect of IGF-1 treatment) in the combination groups, with a rapid return to baseline values. Platelet counts were mildly decreased across the study compared with baseline. This decrease in platelet count was more pronounced in the combination groups, but in all groups the mean platelet counts remained well within the normal range. At year 3, 44 out of 80 patients (55\%) assigned to 1 of the 3 coadministration groups had developed anti-IGF-1 antibodies, which were transient in most cases.

\section{Discussion}

This is the first study to test the effects of coadministration of rhGH and rhIGF-1 in children who have GH sufficiency with low IGF-1 and short stature. Whether such patients would benefit from combined rhGH + rhIGF-I therapy to correct both the short stature and the biochemical abnormalities has been a debated scientific topic in the field of pediatric endocrinology for many years. Some have argued that rhGH alone would be sufficient to treat short stature considering that rhGH is an agent with a known safety profile. Therefore, our study was undertaken to test the hypothesis that in such children, coadministered therapy would result in better growth without undue side effects. The results of our study showed a statistically significant improvement in linear growth for the 45 rhGH +150 rhIGF-1 group (group D) compared with the rhGH alone group at 1 year. The significant difference in $\mathrm{HV}$ observed at year 1 clearly affected the treatment response assessed at years 2 and 3. The HVs for the entire first 2 years (year $1+$ year 2 ) and for all 3 years (year $1+$ year $2+$ year 3 ) remained significantly different. However, the true year 2 and year $3 \mathrm{HV}$ did not achieve significant difference $(\mathrm{p}=0.063$ and $\mathrm{p}=$ 0.872). Therefore, $\mathrm{rhGH} / \mathrm{rhIGF}-1$ coadministration resulted in significantly greater $\mathrm{HV}$ at year 1 only, while still producing an overall greater height gain over the 3 years of the study. This occurred without an undue increase in skeletal maturation or BMI.

The mean first-year HV of $11.2 \mathrm{~cm} /$ year for the 45 rhGH +150 rhIGF-1-treated patients in this study was superior to that of rhIGF-1-treated patients with severe primary IGFD $(8.0 \mathrm{~cm} /$ year at doses of $40-120 \mu \mathrm{g} / \mathrm{kg} / \mathrm{dose}$ twice daily) [5], of IGF-1-treated children with milder IGFD (height and IGF-1 SD scores $<-2 ; 7.0$ and $7.9 \mathrm{~cm} /$ year at doses of 80 and $120 \mu \mathrm{g} / \mathrm{kg}$ once daily) [18], of rhGH-treated children with idiopathic short stature (7.3$8.6 \mathrm{~cm} /$ year at rhGH doses of 33-53 $\mu \mathrm{g} / \mathrm{kg} /$ day) $[9,19-21]$ and was close to the mean $\mathrm{HV}$ of $10 \mathrm{~cm} /$ year to $13 \mathrm{~cm} /$ year previously reported in rhGH-treated children with $\mathrm{GH}$ deficiency $[6,22]$. The first-year HV for the $45 \mathrm{rhGH}$ alone group in our study was also robust, possibly related to study design, including use of a generous rhGH dose and the inclusion of a few children deemed to have entered puberty, but overall still a slightly younger patient population with younger BA compared with other idiopathic short stature populations in rhGH trials [21, 23]. However, caution should be used when comparing trials with differing inclusion criteria and study design [24]. Nevertheless, compared with most studies of rhGH therapy for 
idiopathic short stature, coadministration therapy with lower rhIGF-1 doses ( $45 \mathrm{rhGH} / 50$ rhIGF-1 or $45 \mathrm{rhGH} /$ 100 rhIGF-1) yielded better $\mathrm{HV}$ responses than with rhGH alone. Given that we observed a trend toward increasing significance with these increasing rhIGF-1 doses, it is conceivable that certain patients may grow quite well with a lower-dosed coadministration regimen, and, therefore, further investigation should be considered.

The favorable response observed with $45 \mathrm{rhGH}+150$ rhIGF-1 coadministration therapy may be due to the additional growth-promoting effect from rhIGF-1 superimposed on that of rhGH therapy within a normal IGFBP-3 and ALS setting. Unlike patients with severe GH insensitivity, the patients in this study had normal IGFBP-3 and ALS, which may lead to increased tissue concentrations of IGF-1, including at the growth plate. One could propose that exogenous $\mathrm{GH}$ administration could stimulate the growth plate's resting zone (pre)chondrocyte differentiation and facilitate chondrocyte maturation at all differentiation stages. The added rhIGF-1 treatment may then further mediate chondrocyte maturation, thus allowing for accelerated longitudinal bone growth. The additive effects of combined rhGH and rhIGF-1 therapy on growth have also been documented in hypophysectomized, dwarf and obese Zucker diabetic rats [11, 12]. Moreover, there may be a greater anabolic effect with this combination than with either hormone alone. In adult humans, rhGH + rhIGF-1 are substantially more anabolic than either one alone $[13,25,26]$. However, it should be noted that we were not able to show a correlation between the HV response and trough IGF-1 concentrations. There appeared to be no influence on the pharmacokinetics of GH (data not shown). The concentrations of IGFBP-3 increased in all treatment groups, indicating that potential suppression of endogenous $\mathrm{GH}$ secretion by administration of rhIGF-1 was likely compensated by a stimulatory effect from the exogenously administered rhGH.

As the effects of prolonged exposure to increased IGF1 concentrations are not known - with the exception of the information gained from studying patients with acromegaly - the investigators were asked to implement dose reductions of study drug in patients with IGF-1 SD scores of $>+4$ on $\geq 2$ occasions. Trough IGF- 1 concentrations increased in all groups, and most of all in the combination groups, as did peak IGF-1 concentrations until week 120 . However, we found no correlation between trough IGF-1 values and the time to occurrence of first headache, and we also did not observe changes in facial features. Because we could not show a trend indicating that increased IGF-1 concentrations are associated with better HVs, these dose reductions appear to be warranted. As a result of these dose reductions and missed injections, patients tended not to reach their target rhIGF-1 doses (i.e. $50 \mu \mathrm{g} /$ $\mathrm{kg}$ in group $\mathrm{B}, 100 \mu \mathrm{g} / \mathrm{kg}$ in group C and $150 \mu \mathrm{g} / \mathrm{kg}$ in group $\mathrm{D})$. More frequent dose reductions together with greater change in BA from baseline to year 3 in group D compared with the other groups may account for the lower $\mathrm{HV}$ observed in group D at year 3.

The safety profiles of rhGH and rhIGF-1 overlap in some areas, such as for symptoms associated with $\mathrm{ICH}$, while some are distinct to rhIGF-1, such as the potential for hypoglycemia. No additional safety concerns with coadministration were noted compared with previously reported individual safety profiles [7, 20,27]. The combined safety profile was not markedly different from that of rhGH or rhIGF-1 alone.

ICH was reported in 2 patients receiving coadministered therapy, at a similar incidence to that previously reported [18]. ICH is a documented side effect of both rhGH and rhIGF-1 therapies, although it appears to be a less common occurrence with rhGH therapy than with rhIGF-1 $[5,28]$. Because ICH can occur with either hormone used as monotherapy, there may be more concern about the development of ICH than with rhGH or rhIGF-1 monotherapy alone, and its prevalence will need to be monitored in further studies. Most cases of $\mathrm{ICH}$ are benign and, with appropriate management, reversible, without the need to permanently discontinue therapy. Education of treating physicians is critical to ensure that they monitor for ICH, to allow for appropriate, early treatment and to prevent unnecessary complications. Fundus examinations are, therefore, recommended at initiation of rhIGF-1 therapy, routinely during the course of therapy and upon occurrence of clinical symptoms (e.g. visual disturbances, headache, nausea and/or vomiting).

More adverse events of special interest, including headache and hypoglycemia, were reported in group D. IGF-1, on a molar basis, only has a fraction of insulin's effect on glucose metabolism, but after administration of exogenous IGF-1 it may be present in a high enough concentration to reduce glucose availability [29]. Exogenous GH may decrease insulin sensitivity [30], and could counteract the hypoglycemic effect sometimes observed with rhIGF-1 treatment. The assumption that the addition of rhIGF-1 to rhGH would counterbalance the effect of rhGH alone on carbohydrate metabolism was not confirmed in this study, but the hypoglycemic events that occurred in group D were of mild intensity and did not necessitate a dose reduction. Furthermore, a greater propor- 
tion of patients in group A had elevated glycosylated hemoglobin than in the coadministration groups. Hypoglycemia is a known adverse event with rhIGF-1 therapy and specific guidance is provided to physicians prescribing rhIGF-1 therapy for severe primary IGFD to minimize the risk of hypoglycemia. This includes administering all rhIGF-1 injections simultaneously with a meal, monitoring glucose levels and paying special attention to the risk of hypoglycemia after exercise. For this study, no attempts were made to document the potential relationship between hypoglycemia and the development of headache.

A potential limitation of this study was that pretreatment HVs were not available because a specific pretreatment HV cutoff was not part of the inclusion criteria. As study participants had to be $\geq 5$ years of age and prepubertal, one can assume that the average pretreatment growth velocity was around $5.0-6.5 \mathrm{~cm}$ per year. Furthermore, the administration of two injections per day with coadministration therapy (vs. only one with monotherapy) could lead to decreased long-term compliance and treatment adherence, although there was no evidence of this in this study. An additional limitation is the absence of an rhIGF-1 alone treatment arm. Finally, a significant number of patients entered puberty during the study, possibly affecting treatment response, but when analysis of the HV ANCOVA was done for the pubertal status, it did not affect the observed statistical significance of the primary analysis.

It remains too early to state that combination therapy will ultimately improve adult height beyond rhGH monotherapy intervention. However, recent reports have underscored that clinical expression of GH-IGF-1 axis defects runs along a continuum of genetic, phenotypic and hormonal abnormalities [1,31-33]. The associated IGFD may then reflect the existence of a spectrum of GH sensitivity that is much wider than initially believed based on the extremes of severe GH deficiency or GH insensitivity [34]. The therapeutic applicability of GH-IGF-1 combination therapy may therefore apply to specific subpopulations within the GH-IGF-1 axis continuum, such as GHdeficient patients with suboptimal response to rhGH therapy and patients with milder forms of GH insensitivity.

\section{Conclusion}

In GH-sufficient children with short stature and low IGF-I, coadministration of $45 \mathrm{rhGH}+150$ rhIGF-1 (both $\mu \mathrm{g} / \mathrm{kg} /$ day) significantly accelerated statural growth compared with rhGH monotherapy. A significant difference in $\mathrm{HV}$ between the $45 \mathrm{rhGH}+150$ rhIGF-1 and rhGH alone groups was observed at year 1 . This resulted in a sustained height SD score improvement, as this effect persisted during the second and the third years of treatment. Treatment with $\mathrm{rhGH} / \mathrm{rhIGF}-1$ coadministration was generally well tolerated, with a safety profile similar to the individual monotherapies. Despite these results, we cannot recommend that $\mathrm{rhGH} / \mathrm{rhIGF}-1$ combination therapy be considered for GH-sufficient short children with low IGF-1. However, because in select patients this treatment approach may lead to improved growth compared with either rhGH or rhIGF-1 monotherapy, our findings indicate a need for further studies.

\section{Acknowledgements}

This study was sponsored and funded by Ipsen, France. The authors take full responsibility for the content of this manuscript and would like to thank Communigen Ltd. (Oxford, UK), funded by Ipsen, France, for assisting with the preparation of this manuscript. The authors wish to thank the study coordinators and the other MS316 investigators (listed below), and the following individuals who were involved in the study design and conduct: George Bright, Catherine Lesage, Pascal Birman and Sandra Blethen, as well as Stephen Chang who also contributed to the data analyses. The MS316 Study Group includes, in California, Susan Clark, Ruvdeep Randhawa, Michael Gottschalk, Norman Lavin, Gnanagurudasan Prakasam; in Florida, Larry Deeb; in Georgia, Quentin Van Meter; in Illinois, Richard Levy; in Indiana, John Fuqua; in Massachusetts, Rosalind Brown, Leslie Soyka; in Minnesota, Betsy Schwartz; in Missouri, Maxwell Feldt; in New Jersey, Dennis Brenner, Lawrence Silverman; in Ohio, Douglas Rogers; in Oregon, Katie Woods; in Pennsylvania, Stephen Willi; in South Carolina, Deborah Bowlby; in Texas, Michele Hutchison, Louisa Rodriquez, and in Washington, Patricia Fechner. We would also like to thank the members of the Data Monitoring Committee: Alan Rogol, Mitchell Geffner, Laurie Cohen and Charles DuMond.

\section{Disclosure Statement}

P.F.B. was an investigator on the trial, has been an advisory committee member for Ipsen, has received research funding from Ipsen and Novo Nordisk, and has received consultancy fees from Novo Nordisk, Sandoz and EMD Serono; B.S.M. was an investigator on the trial, has received consultancy fees from Alexion, BioMarin, Ipsen, Genentech, Novo Nordisk, Sandoz and Endo Pharmaceuticals, and has received research funding from Ipsen, Genentech, Pfizer, Novo Nordisk, Eli Lilly \& Company, Sandoz, Endo Pharmaceuticals and AbbVie; P.D. is an employee of Ipsen Innovation; A.H. is an employee of Ipsen Pharma; E.L. is a former employee of Ipsen Biopharmaceuticals; D.E.H. was an investigator on this trial; B.R. was an investigator on the trial, and has received consultancy fees from Ipsen and research funding from Ipsen, Genentech, Pfizer and Novo Nordisk, and M.A.S. has received consultancy fees from Novo Nordisk. 


\section{References}

1 Savage MO, Burren CP, Rosenfeld RG: The continuum of growth hormone-IGF-I axis defects causing short stature: diagnostic and therapeutic challenges. Clin Endocrinol (Oxf) 2010;72:721-728.

$>2$ Hynes MA, Van Wyk JJ, Brooks PJ, D’Ercole AJ, Jansen M, Lund PK: Growth hormone dependence of somatomedin-C/insulin-like growth factor-I and insulin-like growth factor-II messenger ribonucleic acids. Mol Endocrinol 1987;1:233-242.

-3 Lupu F, Terwilliger JD, Lee K, Segre GV, Efstratiadis A: Roles of growth hormone and insulin-like growth factor 1 in mouse postnatal growth. Dev Biol 2001;229:141-162.

4 Ranke MB, Price DA, Albertsson-Wikland K, Maes M, Lindberg A: Factors determining pubertal growth and final height in growth hormone treatment of idiopathic growth hormone deficiency. Analysis of 195 Patients of the Kabi Pharmacia International Growth Study. Horm Res 1997;48:62-71.

$\checkmark 5$ Chernausek SD, Backeljauw PF, Frane J, Kuntze J, Underwood LE: Long-term treatment with recombinant insulin-like growth factor (IGF)-I in children with severe IGF-I deficiency due to growth hormone insensitivity. J Clin Endocrinol Metab 2007;92:902910.

$\checkmark 6$ Cohen P, Bright GM, Rogol AD, Kappelgaard AM, Rosenfeld RG: Effects of dose and gender on the growth and growth factor response to $\mathrm{GH}$ in $\mathrm{GH}$-deficient children: implications for efficacy and safety. J Clin Endocrinol Metab 2002;87:90-98.

7 Backeljauw PF, Chernausek SD: The insulinlike growth factors and growth disorders of childhood. Endocrinol Metab Clin North Am 2012;41:265-282, v.

$\checkmark 8$ Cohen P, Rogol AD, Howard CP, Bright GM, Kappelgaard AM, Rosenfeld RG: Insulin growth factor-based dosing of growth hormone therapy in children: a randomized, controlled study. J Clin Endocrinol Metab 2007; 92:2480-2486.

$>9$ Wit JM, Rekers-Mombarg LT, Cutler GB, Crowe B, Beck TJ, Roberts K, Gill A, Chaussain JL, Frisch H, Yturriaga R, Attanasio AF: Growth hormone $(\mathrm{GH})$ treatment to final height in children with idiopathic short stature: evidence for a dose effect. J Pediatr 2005; 146:45-53.

10 Vaccarello MA, Diamond FB Jr, GuevaraAguirre J, Rosenbloom AL, Fielder PJ, Gargosky S, Cohen P, Wilson K, Rosenfeld RG: Hormonal and metabolic effects and pharmacokinetics of recombinant insulin-like growth factor-I in growth hormone receptor deficiency/Laron syndrome. J Clin Endocrinol Metab 1993;77:273-280.

11 Clark RG, Carlsson LM, Mortensen D, Cronin MJ: Additive effects on body growth of insulin-like growth factor-1 and growth hormone in hypophysectomized rats. Endocrinol Metab 1994;1:49-54.
12 Clark RG, Mortensen DL, Carlsson LM: Insulin-like growth factor-1 and growth hormone $(\mathrm{GH})$ have distinct and overlapping anabolic effects in GH-deficient rats. Endocrine 1995 ; 3:297-304.

3 Kupfer SR, Underwood LE, Baxter RC, Clemmons DR: Enhancement of the anabolic effects of growth hormone and insulin-like growth factor I by use of both agents simultaneously. J Clin Invest 1993;91:391-396.

14 Kuczmarski RJ, Ogden CL, Guo SS, GrummerStrawn LM, Flegal KM, Mei Z, Wei R, Curtin LR, Roche AF, Johnson CL: 2000 CDC growth charts for the United States: methods and development. Vital Health Stat 2002;11:1-190.

15 Roche AF, Wainer H, Thissen D: The RWT method for the prediction of adult stature. Pediatrics 1975;56:1027-1033.

16 Khamis HJ, Guo SS: Improvement in the Roche-Wainer-Thissen stature prediction model: a comparative study. Am J Hum Biol 1993;5:669-679.

17 Roche AF, Davila GH: Late adolescent growth in stature. Pediatrics 1972;50:874-880.

18 Midyett LK, Rogol AD, Van Meter QL, Frane J, Bright GM: Recombinant insulin-like growth factor (IGF)-I treatment in short children with low IGF-I levels: first-year results from a randomized clinical trial. J Clin Endocrinol Metab 2010;95:611-619.

19 Lanes R: Effects of two years of growth hormone treatment in short, slowly growing non-growth hormone deficient children. J Pediatr Endocrinol Metab 1995;8:167-171.

-20 Kemp SF, Kuntze J, Attie KM, Maneatis T, Butler S, Frane J, Lippe B: Efficacy and safety results of long-term growth hormone treatment of idiopathic short stature. J Clin Endocrinol Metab 2005;90:5247-5253.

21 Hintz RL, Attie KM, Baptista J, Roche A: Effect of growth hormone treatment on adult height of children with idiopathic short stature. Genentech Collaborative Group. N Engl J Med 1999;340:502-507.

22 Root AW, Kemp SF, Rundle AC, Dana K, Attie KM: Effect of long-term recombinant growth hormone therapy in children - the National Cooperative Growth Study, USA, 1985-1994. J Pediatr Endocrinol Metab 1998;11:403-412.

23 Leschek EW, Rose SR, Yanovski JA, Troendle JF, Quigley CA, Chipman JJ, Crowe BJ, Ross JL, Cassorla FG, Blum WF, Cutler GB Jr, Baron J: Effect of growth hormone treatment on adult height in peripubertal children with idiopathic short stature: a randomized, doubleblind, placebo-controlled trial. J Clin Endocrinol Metab 2004;89:3140-3148.

24 Finkelstein BS, Imperiale TF, Speroff T, Marrero U, Radcliffe DJ, Cuttler L: Effect of growth hormone therapy on height in children with idiopathic short stature: a metaanalysis. Arch Pediatr Adolesc Med 2002;156: 230-240.
25 Waters D, Danska J, Hardy K, Koster F, Qualls C, Nickell D, Nightingale S, Gesundheit N, Watson D, Schade D: Recombinant human growth hormone, insulin-like growth factor 1 , and combination therapy in AIDS-associated wasting. A randomized, double-blind, placebo-controlled trial. Ann Intern Med 1996;125:865-872.

26 Hatton J, Kryscio R, Ryan M, Ott L, Young B: Systemic metabolic effects of combined insulin-like growth factor-I and growth hormone therapy in patients who have sustained acute traumatic brain injury. J Neurosurg 2006;105: 843-852.

27 Divall SA, Radovick S: Growth hormone and treatment controversy; long term safety of rGH. Curr Pediatr Rep 2013;1:128-132.

-28 Noto R, Maneatis T, Frane J, Alexander K, Lippe B, Davis DA: Intracranial hypertension in pediatric patients treated with recombinant human growth hormone: data from 25 years of the Genentech National Cooperative Growth Study. J Pediatr Endocrinol Metab 2011;24:627-631

29 Boulware SD, Tamborlane WV, Rennert NJ, Gesundheit N, Sherwin RS: Comparison of the metabolic effects of recombinant human insulin-like growth factor-I and insulin. Dose-response relationships in healthy young and middle-aged adults. J Clin Invest 1994;93: 1131-1139.

30 Cutfield WS, Jackson WE, Jefferies C, Robinson EM, Breier BH, Richards GE, Hofman PL: Reduced insulin sensitivity during growth hormone therapy for short children born small for gestational age. J Pediatr 2003;142:113-116.

31 David A, Camacho-Hubner C, Bhangoo A, Rose SJ, Miraki-Moud F, Akker SA, Butler GE, Ten S, Clayton PE, Clark AJ, Savage MO, Metherell LA: An intronic growth hormone receptor mutation causing activation of a pseudoexon is associated with a broad spectrum of growth hormone insensitivity phenotypes. J Clin Endocrinol Metab 2007;92:655-659.

-32 Goddard AD, Dowd P, Chernausek S, Geffner M, Gertner J, Hintz R, Hopwood N, Kaplan S, Plotnick L, Rogol A, Rosenfield R, Saenger P, Mauras N, Hershkopf R, Angulo M, Attie K: Partial growth-hormone insensitivity: the role of growth-hormone receptor mutations in idiopathic short stature. J Pediatr 1997;131:S51-S55.

33 Fang P, Riedl S, Amselem S, Pratt KL, Little BM, Haeusler G, Hwa V, Frisch H, Rosenfeld RG: Primary growth hormone $(\mathrm{GH})$ insensitivity and insulin-like growth factor deficiency caused by novel compound heterozygous mutations of the $\mathrm{GH}$ receptor gene: genetic and functional studies of simple and compound heterozygous states. J Clin Endocrinol Metab 2007;92:2223-2231.

34 David A, Hwa V, Metherell LA, Netchine I, Camacho-Hubner C, Clark AJ, Rosenfeld RG, Savage MO: Evidence for a continuum of genetic, phenotypic, and biochemical abnormalities in children with growth hormone insensitivity. Endocr Rev 2011;32:472-497. 